\title{
O FIM DA HIERARQUIA FAMILIAR? AS NOVAS INTERPRETAÇÕES PARA O DIREITO DAS SUCESSÕES A PARTIR DA REDEFINIÇÃO DOS CONCEITOS DE FAMÍLIA E SEU IMPACTO NA CODIFICAÇÃO CIVIL
}

\author{
OLIVEN, Leonora Roizen Albek*
}

O trabalho faz a interlocução entre institutos do direito civil contemporâneo a partir da decisão do Supremo Tribunal Federal de maio de 2017 sobre as diferenças de regime sucessório entre cônjuge e companheiro. Ao declarar inexistir hierarquia entre as entidades familiares, alarga a atuação e proteção às famílias plurais e abre espaço para novas interpretações e aplicações da codificação civil. A discussão será realizada com a historicidade e a análise de formação das então novas entidades familiares, da sucessão dos companheiros e dos cônjuges com um quadro comparativo entre os sistemas, considerando como necessária a similitude nos efeitos jurídicos.

PALAVRAS-CHAVE: sucessões; cônjuge; companheiro; diferenças; hierarquia.

The end of the family hierarchy? The new interpretations of the law of successions from the redefinition of family concepts and their impact on civil codification

This paper propose interlocution between institutes of contemporary civil law from the decision of the Federal Supreme Court, May 2017 on the differences of succession between spouse and partner. In declaring that there is no hierarchy among family entities, it extends the action and protection to plural families and for new interpretations of civil code. The discussion will be carried out with the historicity and analysis of the formation of the then new family entities, of the succession of the companions and the spouses with a comparative picture between the systems, considering as necessary the similarity in the legal effects.

KEY WORDS: successions; spouse; companion; differences; hierarchy. 


\section{INTRODUÇÃO}

O trabalho dialoga com a decisão do Supremo Tribunal Federal (STF), proferida no Tribunal Pleno em 10 de maio de 2017 nos recursos extraordinários RE 878694 / MG e RE 646.721/RS e o seu alcance na interpretação da codificação civil. Com repercussão geral da questão constitucional suscitada sobre as diferenças de regime sucessório entre cônjuge e companheiro" ${ }^{1}$, ela julgou no mérito que "É inconstitucional a distinção de regimes sucessórios entre cônjuges e companheiros prevista no art. 1.790 do CC/2002, devendo ser aplicado, tanto nas hipóteses de casamento quanto nas de união estável, o regime do art. 1.829 do CC/2002"

$\mathrm{O}$ reconhecimento da inexistência de hierarquia entre as entidades familiares amplia a proteção às famílias plurais. Configuradas sob os mais diversos aspectos afetivos e sociais, agora os efeitos são analisados em sede de direito sucessório. Para atribuir os direitos post mortem, se faz necessário refletir sobre esses formatos. Elas advêm do matrimônio ou da união estável, são hetero ou homoafetivas, têm diferentes acomodações sem que isso implique em redução de direitos típicos das famílias nos estatutos pessoais, patrimoniais ou assistenciais. O espaço de igualdades em direitos prescinde das diferenças na formação das famílias.

$\mathrm{O}$ assunto proposto discute determinados efeitos jurídicos para as famílias formais e informais, considerando a inexistência de posição de (des)vantagem entre elas. A pesquisa confrontará alguns aspectos da aplicação das normas de direito civil nos casos que têm similitude fática e diferentes soluções jurídicas, enfrentando os impactos decorrentes da pluralidade familiar, inclusive através de sua historicidade.

Os desfechos discrepantes para situações com análogas questões de fundo para cada um dos institutos justifica o estudo, sendo necessário o enfrentamento para evitar o retrocesso social e realizar direitos civis e sociais fundamentais às famílias. Há paradoxos que cristalizam a desigualdade. A finalidade em verificar possíveis novas interpretações sobre o Código Civil (CC) é dar efetividade à decisão que garante a equidade nas famílias sob os mais

*Doutora em Direito do Programa de Pós-Graduação em Direito da Universidade Veiga de Almeida, mestre me Psicanálise, Saúde e Sociedade pela Universidade Veiga de Almeida. Docente colaboradora do PPGD-UVA, docente de graduação UVA e IBMEC, Rio de janeiro. Endereço de email: leonora.oliven@gmail.com e endereço para acessar o lattes http://lattes.cnpq.br/1070351326253691

${ }^{1}$ O Tribunal, apreciando o tema 809 da repercussão geral, por maioria e nos termos do voto do Ministro Relator, deu provimento ao recurso, para reconhecer de forma incidental a inconstitucionalidade do art. 1.790 do CC/2002 e declarar o direito da recorrente a participar da herança de seu companheiro em conformidade com o regime jurídico estabelecido no art. 1.829 do Código Civil de 2002. Disponível em http://portal.stf.jus.br Acesso em 17 out. 2018.

2 Disponível em http://portal.stf.jus.br Acesso em 17 out. 2018. 
diversos aspectos. Há projetos de $\mathrm{lei}^{3}$, ou ainda projetos de projetos, com o objetivo de modificar o Código Civil em artigos referentes à posição jurídica de cônjuges e companheiros, pois ela alcançará as situações similares cujos inventários ainda não tenham sido concluídos.

Para compreender os conceitos e descrever as principais características, similitudes e diferenças das famílias e do direito sucessório, a metodologia na qual o trabalho se apoiará é a pesquisa bibliográfica. A leitura e interpretação de textos normativos, decisões judiciais e doutrina especializada orientam a investigação, com análise crítica das aplicações. Ela não vai encarar as famílias de forma idêntica, mas exatamente considerar as peculiaridades para dar identidade a cada uma delas sem deixar de atribuir a proteção legal.

2. O reconhecimento das famílias informais.

Os debates sobre a sucessão dos cônjuges movimenta o Direito Civil. Na legislação de 1916 ela foi introduzida de forma tímida, sendo o terceiro vocacionado e apenas em não havendo descendentes e ascendentes. A partir do Estatuto da Mulher Casada, de 1962, amplia-se o cuido à família através da instituição do usufruto vidual e do direito real de habitação. Discutia-se então sobre a posição jurídica de herdeiro facultativo e a necessidade em torná-lo necessário, como na legislação atual, ou ainda a inexistência de direitos aos conviventes, implementados em 1994. As diferenças, progressos e resistências são objeto de discussões doutrinárias e jurisprudenciais, ainda havendo dúvidas e interpretações díspares sobre o formato.

O tema ficou ainda mais perceptível com o Código Civil de 2002, que incluiu o cônjuge sobrevivente como como herdeiro necessário e de forma peculiar disciplinou a sucessão do companheiro em outro modelo. Ficaram evidentes as contundentes discrepâncias entre as famílias. Também revelou o retrocesso aos direitos anteriormente conquistados pelas normas que trataram especificamente das relações convivenciais ${ }^{4}$.

A união estável não é novidade no Brasil. É um fato jurídico inicialmente identificado em casais que não queriam formalizar o vínculo ou que não podiam casar. Eram diversos os impedimentos e no caso adviriam da unicidade de gênero ou por não haver divórcio como meio hábil a dissolver o matrimônio pela manifestação da vontade, por ato inter vivos. Ele só

\footnotetext{
${ }^{3}$ Projeto de Lei da Câmara dos Deputados no 508, de 2007; Projeto de Lei do Senado Federal no 6.896, de 2017.

${ }^{4}$ Lei no 8971/1994 e Lei no 9278/1996.
} 
ingressa no ordenamento com essa atribuição em $1977^{5}$. As pessoas passam a conviver com a possibilidade de querer ou não a formalização do vínculo.

O direito de muitas formas rechaçava esses ajustes familiares. Com denominações preconceituosas, como concubinato, palavra em desuso pelo viés pejorativo, ou casal amigado, essas famílias sofriam restrições. Havia impedimentos a novos casamentos, aos registros civis de filhos havidos fora do casamento, ou ainda a constituição de patrimônio familiar decorrentes dessas relações, revelando o desprestígio das uniões. Aos poucos se foi buscando soluções para corrigir as distorções, mas o percurso foi longo e lento.

Considerado como a única possibilidade de constituir a família legítima, capaz de atribuir o nome familiar, patrimônio, direito e deveres, o casamento foi inicialmente religioso e permitido apenas entre os católicos. A partir das uniões entre acatólicos ${ }^{6}$ e da instituição do casamento civil ${ }^{7}$, formas de fortalecer a laicidade do Estado, amplia-se o escopo de proteção normativa às famílias. Mas não é suficiente. Muitas delas permaneceram à margem de todo e qualquer direito, considerando então a necessidade de formalização através do matrimônio.

Ainda assim, é possível encontrar em algumas normas especiais algum tipo de proteção às famílias informais. É o caso do decreto de $1912^{8}$ que regula a responsabilidade civil das estradas de ferro e reconhece a legitimidade de todos os dependentes econômicos da vítima à indenização. Trata-se de cláusula geral, legitimando filhos havidos fora do casamento e conviventes em dependência econômica à propositura da ação. Em 19449 , é reconhecido à companheira dependente economicamente o direito à percepção de benefícios previdenciários por morte do trabalhador, bem como a todos os filhos. São demandas que paulatinamente vão obtendo respostas satisfatórias.

O movimento acelerou a partir dos anos de 1960. A segunda onda do feminismo fortalece a demanda pelo direito ao corpo, a liberdade sexual, às escolhas e pela atribuição de direitos civis às mulheres. As discussões sobre as diferenças entre sexo e gênero avivam as identidades atuam para mitigar e colocar fim à naturalização da posição de vantagem do homem. A partir da percepção de realidade que o casamento não é fonte única da felicidade e

\footnotetext{
${ }^{5}$ EC n $^{\circ}$ 9/1977 e Lei no 6.515/1977, Lei do Divórcio.

${ }^{6}$ Lei $\mathrm{n}^{\circ} 1.144$ de 11 de setembro de 1861 , complementada pelo regulamento $\mathrm{n}^{\circ} 3.069$ de 17 de abril de 1863 .

${ }^{7}$ Decreto-Lei $n^{\circ} 181$ de 24 de janeiro de 1890.

${ }^{8}$ Decreto $\mathrm{n}^{\mathrm{o}} 2.681$, de 7 de dezembro de 1912, art. 22- No caso de morte, a estrada de ferro responderá por todas as despesas e indenizará, a arbítrio do juiz, todos aqueles aos quais a morte do viajante privar de alimento, auxílio ou educação.

${ }^{9}$ Decreto-Lei no $7.036 / 1944$.
} 
de sucesso para a mulher e que parte dele advém do poder sobre o próprio corpo e da autonomia econômica, amplia-se a luta pela igualdade de direito aos estudos e ao trabalho.

Para o direito das famílias, o movimento repercute com o Estatuto da Mulher Casada $^{10}$. Ainda que imperfeito, a conquista da integralização da capacidade civil para as mulheres casadas, o fim da tutela marital na liberdade para a escolha de trabalhos extramuros conjugais, bem como no regime de bens particulares para aqueles adquiridos com fruto exclusivo do trabalho, despontam novos ambientes de realização de direitos.

Com os vinte e seis anos de luta pelo divórcio, a dissolução do vínculo conjugal tornou possível regularizar as novas famílias, mas desde que formalizadas. Ele exigia tempo e causa, desgastando ainda mais as relações já esgarçadas ao exigir a discussão sobre a culpa, cristalizando os litígios, expondo o ex-casal e judicializando a família.

As outras formas de organização familiares já existiam. Elas eram fáticas, concretas, mas sem o reconhecimento legal em todos os espectros, o que se tornou categórico tão somente a partir da Constituição Federal de 1988 (CF/88). Nos debates, Mendes Ribeiro, congressista conhecedor das diferenças jurídicas das famílias formais e informais, no amor enxerga a essência da família. Para ele, "A união sem amor jamais será família” (MENDES RIBEIRO, 1987, p. 210), fortalecendo a ideia de afeto na sua composição.

As responsabilidades conjuntas, financeiras e familiares, unem as pessoas de uma forma íntima. A confirmação é cotidiana e depende da contribuição de cada um, individualmente e em grupos de proteção e desenvolvimento pelo que se acredita e se confia como valor maior da palavra. Ao direito, cabe resguardar os efeitos desses compromissos.

Surge então outro ponto: a Constituição Federal de 1988, promulgada na vigência do Código Civil de 1916, exigia soluções que comportassem os avanços sociais e a nova ordem jurídica. O reconhecimento de que a ausência de normas específicas caracterizaria a igualdade jurídica na pluralidade das famílias, com equidade e justa medida para todas elas era oposto com resistências às uniões convivenciais, tornando necessário assegurar os direitos dessas famílias. Sob o argumento desse vazio legislativo sobre a união estável, só a partir da Lei $n^{\circ}$ 8971/1994 será possível atribuir direitos sucessórios aos companheiros e com a Lei $n^{\circ}$ 9278/1996, havendo para cônjuges e companheiros identidade jurídica de direitos e deveres das famílias e das sucessões.

${ }^{10}$ Lei no $4121 / 1962$. 
3. A sucessão do companheiro.

À época do reconhecimento das uniões informais como entidades familiares, tramitava no Congresso Nacional o Projeto para o Código Civil. É proposto certo distanciamento do formalismo jurídico para permitir que o julgador se utilize mais da equidade, aproximando o direito da realidade humana e do mundo real, chamado por Reale de mundo moral, e reconhece a importância em "adequar a lei civil às exigências de nosso tempo" (REALE, 1975, p. 31). Couto e Silva ${ }^{11}$, relator do projeto em Direito de Família, realça a importância de a norma acompanhar a realidade social (COUTO E SILVA, 2012, p.219), o que torna necessário conhecer a as configurações das famílias brasileiras.

O anteprojeto de 1965 menciona em específico o direito das sucessões às companheiras mulheres como forma de corrigir injustiças e sugere a partilha da herança através de quinhões desiguais, e em melhores condições do que as posteriormente positivadas no art. 1790 da Lei 10.406/2002. Já o Projeto de 1975 deixou o tema à margem, com expressa menção a esse descuido ${ }^{12}$. Oscilava-se entre a necessária adequação de direitos e o espírito social conservador, de permanência ao mesmo estado das coisas então existentes.

Era um projeto inclusivo para os cônjuges sobreviventes, impondo o casamento. Ao reconhecer que a viuvez demanda uma proteção patrimonial diferenciada e jurídica para o cônjuge, ele foi instituído como herdeiro necessário privilegiado. Torna-se concorrente de forma concomitante com os descendentes, com os ascendentes e ainda recolhendo a herança por inteiro como terceiro vocacionado, "portanto, ora está na 1a classe dos herdeiros legítimos, concorrendo com os descendentes, ora na 2a classe sucessória, concorrendo com os ascendentes, e ocupa, sozinho, a 3 a classe dos sucessíveis" (VELOSO, 2001). Mas não foi atribuída a mesma atenção aos companheiros.

A partir do texto constitucional de 1988, com o reconhecimento das famílias formadas pela união estável, ainda que incluída pelo Senador Nelson Carneiro a orientação de facilitar a sua conversão em casamento, busca-se a adequação na legislação civil. Ela precisará incorporar também as conquistas já obtidas com as legislações específicas. São apresentadas

${ }^{11} 5^{\text {a }}$ Reunião para o Projeto de Código Civil. Conferência do Professor Clóvis Veríssimo do Couto e Silva acerca do Projeto de Lei n ${ }^{\circ}$ 634, de 1975, do Poder Executivo, que dispõe sobre o Código Civil. Fonte: Arquivo da Câmara dos Deputados. Disponível em http://codigo_civil_debate_v1_tomos1a4\%20.pdf acessado em 25 out. 2018.

${ }^{12}$ Livro V, Do Direito das Sucessões, e Livro Complementar, Disposições Finais e Transitórias Deputado Raimundo Diniz / Celso Barros. Projeto de Lei no 634, de 1975, do Poder Executivo, que dispõe sobre o Código Civil. Fonte: Arquivo da Câmara dos Deputados. Disponível em http://codigo_civil_debate_v1_tomos1a4.pdf acessado em 25 out. 2018.

Rev. de Direito de Família e Sucessões | e-ISSN: 2526-0227 | Goiânia| v. 5 | n. 1 | p. 1-20| Jan/Jun. 2019 
emendas para incluir os então artigos 1865 A, B e C. Nesse projeto ${ }^{13}$, vincula-se a sucessão dos companheiros a atualidade da união, inclui-se o usufruto vidual e o direito real de habitação, tornando-o terceiro vocacionado a suceder e sem concorrer com descendentes e ascendentes.

Posteriormente surgem novos arranjos, distanciando cada vez mais a sucessão do cônjuge da do companheiro. A inclusão do artigo 1.790 no Código Civil ora vigente sob o título Disposições Gerais no livro de Direito das Sucessões já demonstra atecnia. Ele deveria estar localizado em Da Ordem da Vocação Hereditária, dela trata, no entanto está localizada nas Disposições Gerais sobre o direito sucessório. Considerada como "evidente erro de técnica legislativa, por não vir constando a sua inclusão na mesma parte do Código que estabelece a ordem da vocação hereditária em geral" (RIZZARDO, 2018), a regra cria diferentes sistemas sucessórios. Como se o legislador se sentisse desconfortável, e é apenas uma suposição para que se perdesse dessa forma, aborda do tema tão somente nesse ambiente, como se não houvesse uma vocação hereditária em favor de herdeiros conviventes.

A normativa também se afastou dos direitos consolidados nas legislações anteriores. $\mathrm{O}$ retrocesso é perceptível, pois retirara direitos dos companheiros, além de criar uma subclasse familiar advinda da união estável. A existência de dois sistemas sucessórios por si só indica a preferência da codificação. De outro lado, a comparação entre o sistema sucessório vigente de 1998 até a entrada em vigor do Código Civil de 2002 demonstra e potencializa as diferenças entre a sucessão do companheiro e a do cônjuge sobrevivente.

Nesse período entre as codificações, foi possível a caracterização de igualdade jurídica sucessória. Cônjuges e companheiros eram herdeiros facultativos, terceiros vocacionados na ordem da vocação hereditárias, com o direito real de habitação e o usufruto vidual garantidos como meios de prover a sua dignidade.

A interpretação literal do Código Civil de 2002 implicaria na alteração dessa condição, importando em famílias de primeira e de segunda classe. Essa perspectiva viola a igualdade jurídica entre as famílias, a liberdade de escolha e pluralidade em sua formação, contrariando a personalização que a Constituição Federal de 1988 exige.

4. O companheiro e o cônjuge como herdeiros necessários a partir da vigência do Código Civil 2002.

${ }^{13}$ PL $118 / 1984$. 
Para tornar possível o debate, parte-se da premissa que o companheiro é herdeiro necessário em qualquer hipótese, seja por estar incluído no rol de herdeiros de que trata a ordem da vocação hereditária no art. 1.829 do CC, em identidade com o cônjuge, ou ainda se porventura se aplicasse o ora inconstitucional art. 1.790 do CC. O companheiro é herdeiro concorrente em ambas hipóteses legais, devendo então ser considerado herdeiro necessário (LÔBO, 2018).

A partir daí, verifica-se que o companheiro, assim como o cônjuge sobrevivente, tem dupla vocação. Ele é herdeiro concorrente de forma concomitante com descendentes e ascendentes e ainda acumula a posição de terceiro vocacionado exclusivamente na ordem da vocação hereditária.

Para que o companheiro suceda, assim como o cônjuge, ele deve ter legitimidade sucessória. No entanto, o art. 1.830 do $\mathrm{CC}$ cuida tão somente dos requisitos atribuídos ao cônjuge para a sucessão, não mencionando o companheiro. Não faz sentido essa exclusão, pois não seria razoável atribuir direitos hereditários ao companheiro se a união não fosse contemporânea ao óbito. Isso implica considerar que ela também deverá ter atualidade na relação familiar. A configuração da união estável deverá ser provada, ainda que de forma incidental.

A temporalidade da separação de fato há menos de dois anos ou a possibilidade de suceder desde que o sobrevivente não tenha culpa pelo fim da relação familiar aplica conceitos e ideias que não mais harmonizam com o direito das famílias.

As críticas têm como ponto de partida a fixação de prazo mínimo de dois anos. Esse prazo é o mesmo do divórcio direto anterior à vigência da Emenda Constitucional nº 66/2010. Desde o início ele está em desarmonia com o sistema familial: o $§ 1^{\circ}$ do art. 1.723 do CC, que admite a união estável para pessoas casadas desde que separadas de fato, não fixa tempo limite para dar início ao novo relacionamento. Nada justifica garantir herança aos cônjuges ou companheiros separados há menos de dois anos, não há vínculo jurídico entre eles. Permitir a sucessão contraria as regras até mesmo de solidariedade familiar, podendo constituir um favorecimento sem causa. Se há o desejo de proteção, ele poderá ser exercitado em testamento, não havendo qualquer restrição a tais deixas testamentárias.

O outro ponto refere-se à caracterização de culpa póstuma para atribuir legitimidade sucessória. A culpa não é elemento necessário ao término ou dissolução da sociedade conjugal, do vínculo ou da união estável. A decisão pelo fim da relação é direito potestativo 
incondicionado. Não há sentido em discutir descumprimento aos deveres advindos do casamento ou da união estável pelo falecido, que sequer poderá produzir ou contribuir com alguma prova em favor de seus herdeiros. A discussão da culpa parece um autorizativo à exposição ao poder público de temas que pertencem ao privado, por direito e por afeto. Não há "interesse público em investigar a intimidade de um casal e encontrar culpados ou inocentes" (PEREIRA, 2016), e essa procura serve tão somente à satisfação da ferida narcísica de um dos integrantes do ex-casal.

Sustenta-se então que a legitimidade sucessória do companheiro é idêntica a do cônjuge: atual para permitir a transmissão hereditária. Atribuir bens àqueles que não participavam ativamente da convivência do autor da herança poderia caracterizar enriquecimento sem causa, pois faltam os elementos de convivência e de assistência mútua que permita a transferência de bens.

\section{A proteção à moradia.}

O direito real de habitação garante ao supérstite, em todos os regimes de bens, permanecer morando gratuitamente no único imóvel de residência do então casal e tem por finalidade permitir ao sobrevivo a sua moradia nas mesmas condições anteriores, evitando seja privado de sua casa por razões arbitrárias impostas pelos herdeiros. É uma medida de dignidade e de proteção na viuvez. Acredita-se que a perda do cônjuge ou do companheiro não deve vir acompanhada do desalijo do lar conjugal, ficando ao mesmo tempo sem o parceiro e sem o lar, o que atingiria duplamente o sobrevivente.

Ao considerar que a garantia ao direito de moradia decorre da solidariedade familiar (LÔBO, 2018), identifica-se que a sua instituição se dá para fins de assegurar a residência na viuvez, criando limites ao direito, que é inalienável. A atribuição ao supérstite, vitalícia e incondicional, exige que o falecido seja o proprietário do bem imóvel, e independe do regime de bens do casamento (Carvalho, 2017) ou da união estável, o que torna, como regra, uma restrição ao direito de propriedade dos demais herdeiros. Eles se submeterão à limitação do direito real de habitação legal instituído em favor do cônjuge e do companheiro sobrevivente, garantindo o seu direito à moradia em conformidade com a dignidade necessária.

Há situações em que o titular do direito real de habitação não suporta o ônus de sustento do imóvel ou não possui renda que suporte a sua sobrevivência ou ainda outro lugar para residir. Surge então a questão sobre a possibilidade de outras formas de fruição do bem 
objeto do direito, em especial quando importa ao pagamento das despesas com o próprio bem (FROTA, 2016), ou ainda através da locação do imóvel e a utilização dos frutos para a manutenção do sobrevivente. Seria uma forma de garantir a subsistência e a moradia do sobrevivo, ainda que não exatamente no imóvel objeto do direito. Sendo a questão de fundo a proteção à moradia digna, permitir a locação não afastaria efetivamente da razão de ser do instituto.

Essa solução é rejeitada pelo Superior Tribunal de Justiça (STJ), que inadmite a utilização do imóvel de forma diversa à de residência para o exercício do direito real de habitação para o companheiro ou para o cônjuge sobrevivente, reconhecendo que o direito deve ser idêntico a ambos ${ }^{14}$. Usando como paradigma a lei de conviventes de 1998 e o Código Civil de 1916, considerando a data da abertura da sucessão objeto do recurso, mas havendo similitude com a lei ora vigente, o direito real de habitar é gratuito e permite tão somente ao seu titular ocupar o imóvel com a sua família ${ }^{15}$, sem que haja fruição. Ele é personalíssimo, de forma que não se transmite. O cônjuge ou o companheiro sobrevivente deve ocupar pessoalmente o imóvel, sob o risco de ser configurado abuso de direito.

Caso o supérstite não deseje permanecer no imóvel ou dele se utilizar, poderá renunciar ao direito real de habitação sem que a decisão afete a sua participação na herança ${ }^{16}$, caso cumule a posição de herdeiro. Não há cisão na aceitação do quinhão hereditário, o que é vedado ${ }^{17}$. O direito real de habitação não é herança, mesmo sendo um direito sucessório. Trata-se de direito real de habitação sobre coisa alheia, legal e limitado, enquanto aquela é uma universalidade de direitos.

A concorrência sucessória do viúvo, aliada ao direito real de habitação, implicou na opção pela extinção do usufruto vidual. Na codificação civil de 1916, o direito real de habitação seria instituído em favor do cônjuge casado pelo regime da comunhão universal de bens, geralmente meeiro da totalidade do patrimônio familiar. O usufruto vidual era atribuído ao cônjuge casado pelos demais regimes, passando a usufruir de parte do patrimônio do falecido caso não sucedesse em propriedade. Verifica-se a preocupação com as consequências do falecimento de um cônjuge e companheiro na existência pessoal e patrimonial do outro.

\footnotetext{
${ }^{14}$ STJ, Recurso Especial no 1.654 .060 - RJ (2013/0364201-8), Rel. Ministra Nancy Andrighi, Terceira Turma, julgado em 02/10/2018, DJe 04/10/2018. Disponível em https://ww2.stj.jus.br.

15 Art. 1.414 do Código Civil.

${ }^{16}$ III Jornada de Direito Civil, CJF, Enunciado 271: O cônjuge pode renunciar ao direito real de habitação nos autos do inventário ou por escritura pública, sem prejuízo de sua participação na herança.

17 art. 1.808 do Código Civil.
} 
Sobre a temporalidade do direito real de habitação, a lei não a delimita. Se na codificação de 1916 havia como requisito o estado civil de viúvo, a atual não fixa prazo. Acredita-se que a melhor solução seja a análise individualizada de cada caso, privilegiando a finalidade do instituto: a garantia à moradia. Em novo casamento ou união estável do viúvo, deve-se verificar se há outros bens imóveis suscetíveis de residência da nova entidade familiar para não mais restringir a propriedade dos demais herdeiros.

O artigo 1831 do CC atribuiu o direito real de habitação ao cônjuge, deixando de referir o companheiro sobrevivente, com esse direito garantido anteriormente na Lei $\mathrm{n}^{\circ}$ 9278/96, o que aparece como recuo na proteção ao núcleo familiar. A doutrina e jurisprudência estenderam a proteção do direito real ao companheiro $^{18}$, garantindo ao companheiro a mesma dignidade e proteção que ao cônjuge.

6. Os quinhões hereditários evidenciam as preferências.

As situações de (des)vantagem em relação à sucessão do cônjuge sobrevivente em comparação de quotas sucessórias, com diferentes e prejudiciais frações na concorrência com descendentes comuns, não mais se aplicam a partir da decisão do STF. Se até então os diferentes quinhões hereditários demonstravam o viés conservador pelo casamento em detrimento às uniões informais, a hermenêutica constitucional, interpretando o texto legal, deixa claro que não há hierarquia entre as famílias.

Esclarecidos esses pontos, é possível comparar os sistemas sucessórios em diversos aspectos. Inicialmente, a questão referente aos regimes de bens sucessíveis. No casamento, não sucedem a)os casados pelos regimes da comunhão universal de bens, considerando que nesse regime de bens em regra todos os bens compõem um único acervo familiar, de forma que com o óbito entrega-se a meação ao sobrevivente meeiro e a meação que caberia ao falecido deverá ser partilhada pelos descendentes; b) os casados pelo regime da separação obrigatória de bens, impedindo qualquer tipo de transmissão hereditária, exceto a que trata a SUM 370 do STF, que permite a comunicabilidade de bens adquiridos onerosamente na constância da união.

\footnotetext{
${ }^{18}$ I Jornada de Direito Civil, CJF, Enunciado 117: Art. 1831: o direito real de habitação deve ser estendido ao companheiro, seja por não ter sido revogada a previsão da Lei n. 9.278/96, seja em razão da interpretação analógica do art. 1.831, informado pelo art. $6^{\circ}$, caput, da $\mathrm{CF} / 88$.
} 
De outro lado, sucedem os casados pelo regime da comunhão parcial de bens, de participação final de aquestos e os casados pelo regime da separação convencional de bens. Nesses casos, a sucessão incidirá tão somente sobre os bens particulares. Os bens eventualmente comuns serão objeto tão somente da meação, e a meação do falecido será entregue na totalidade aos descendentes, não ao cônjuge.

Na união estável, havia uma depreciação do papel do companheiro, que só sucederia nos bens adquiridos na constância da união estável. O sistema apresenta distorções relevantes em relação ao casamento, seja pela escolha do tipo de união, formal ou informal, a ser adotada pelo casal a partir dos bens porventura já existentes, ou por simplesmente distar na totalidade da formo como os cônjuges sucedem, caracterizando a preferência pelo casamento.

No que se refere à concorrência de descendentes, a sucessão decorrente do matrimonio prevê a reserva legal de 1/4 na concorrência do cônjuge herdeiro quando ele é ascendente dos descendentes com quem concorre e o quinhão idêntico quando não for ascendente dos descendentes concorrentes ou houver pluralidade familiar ${ }^{19}$. Na união estável, o companheiro concorreria com os descendentes dos quais é ascendente com o mesmo quinhão hereditário e tão somente sobre a meação que pertenceria ao companheiro falecido - e receberia uma quota correspondente à $1 / 2$ da cota do herdeiro descendente caso não seja seu descendente ou ainda seja filiação híbrida (HIRONAKA, 2007).

No caso da reserva legal em favor do sobrevivente, a regra pretende garantir ao sobrevivente um quinhão relevante dos bens particulares, já que a meação é um direito próprio, inclusive sendo possível haver vantagem patrimonial em relação aos filhos (LÔBO, 2018). A diferença entre os quinhões desenha o desprestígio na sucessão de companheiros em comparação aos cônjuges. Gera o reconhecimento de uma família de segunda classe, rebaixada pelo legislador a ponto de permitir tais discrepâncias. Também havia desigualdade na concorrência com os ascendentes. Acredita-se que a distorção possa ser sanada com o ajuste do art. 1837 do CC. Na sucessão de cônjuge com ascendentes, haverá a concorrência qualquer que seja o regime de bens e sobre toda a herança. Cai a regra dos bens particulares. Já os companheiros sucederiam tão somente sobre os bens adquiridos onerosamente durante a união. Em relação aos quinhões, concorrendo o cônjuge com ambos os pais do falecido, receberá $1 / 3$ da herança, assim como o companheiro. No entanto, caso o cônjuge concorra com apenas um dos ascendentes em primeiro grau ou com ascendentes em

${ }^{19}$ V Jornada de Direito Civil, CJF, Enunciado 527 - Art. 1.832. Na concorrência entre o cônjuge e os herdeiros do de cujus, não será reservada a quarta parte da herança para o sobrevivente no caso de filiação híbrida. 
grau superior, a ele caberá $1 / 2$ da herança, enquanto que o companheiro continuará a receber tão somente a fração de $1 / 3$.

Após, não havendo descendentes ou ascendentes concorrentes, o cônjuge recolhe a herança por inteiro, ressalvado a possibilidade de haver testamento válido dispondo tão somente sobre a parte disponível. Já o companheiro deveria concorrer com os colaterais do autor da herança, recebendo o quinhão de $1 / 3$ dessa enquanto os colaterais poderiam receber os $2 / 3$ complementares. A possibilidade desprestigia as uniões e os relacionamentos afetivos na totalidade, relegando o companheiro a um papel secundário na história das famílias. Essas incoerências justificam a inclusão do companheiro no art. 1838 do CC, obstando a pretendida concorrência com os colaterais.

7. Comparações entre os sistemas sucessórios antes da decisão do Supremo Tribunal Federal.

O sistema sucessório de cônjuges e companheiros teve momentos peculiares: na vigência das leis nº 8971/1994 e no 9278/1996 de forma conjunta ao Código Civil de 1916, foi possível encontrar similitude jurídica nos direitos sucessórios com as posições de herdeiros facultativos e terceiros vocacionados na ordem da vocação hereditária, direito ao usufruto vidual e ao direito real de habitação.

Com a passagem para o Código Civil de 2002, que se propõe a dialogar de frente com a Constituição Federal de 1988, valorizando a dignidade da pessoa humana e repersonalizando o direito, foram identificadas discrepâncias depreciativas das uniões informais. O quadro comparativo foi elaborado especificamente para essa pesquisa e demonstra as diferenças nos sistemas sucessórios e as vinculações resultantes.

\begin{tabular}{|l|l|lr|}
\hline Código Civil 2002 & $\begin{array}{l}\text { CASAMENTO ART. 1829 } \\
\text { CC }\end{array}$ & $\begin{array}{l}\text { UNIÃO ESTÁVEL ART. } \\
1790 \text { CC }\end{array}$ \\
\hline DIREITO A MEAÇÃO & $\begin{array}{l}\text { Sim, direito próprio } \\
\text { dependente do regime de } \\
\text { bens. }\end{array}$ & $\begin{array}{l}\text { Sim, direito próprio } \\
\text { dependente do regime de } \\
\text { bens. }\end{array}$ \\
\hline $\begin{array}{l}\text { SUCESSÃO EM BENS } \\
\text { COMUNS }\end{array}$ & Não & $\begin{array}{l}\text { Bens } \\
\text { onerosamente ravidos } \\
\text { constância da união r }\end{array}$ \\
\hline
\end{tabular}


Leonora Roizen Albek Oliven

\begin{tabular}{|c|c|c|}
\hline $\begin{array}{l}\text { SUCESSÃO EM } \\
\text { PENS } \\
\text { PARTICULARES }\end{array}$ & $\begin{array}{l}\text { Sim, em todos os bens } \\
\text { particulares. }\end{array}$ & $\begin{array}{l}\text { Bens } \\
\text { onerosamente navidos } \\
\text { constância da união }\end{array}$ \\
\hline & art. $1829 \mathrm{CC}$ & $\mathrm{CC}$ \\
\hline $1 / 4$ & $\overline{\mathrm{CC}}$ & Vão \\
\hline $\begin{array}{l}\text { CONCORRENCIA COM } \\
\text { DESCENDENTES } \\
\text { COMUNS }\end{array}$ & $\begin{array}{l}\text { Sim, com reserva legal de } \\
1 / 4 \text { ou quinhão idêntico ao } \\
\text { dos descendentes, o que for } \\
\text { maior. }\end{array}$ & $\begin{array}{llr}\text { Sim, com } & \text { quinhões } \\
\text { idênticos } & \text { ao } & \text { dos } \\
\text { descendentes. } & & \\
& \end{array}$ \\
\hline $\begin{array}{l}\text { CONCORRENCIA COM } \\
\text { DESCENDENTES SÓ DO } \\
\text { DE CUJUS }\end{array}$ & $\begin{array}{l}\text { Sim, com } \quad \text { quinhões } \\
\text { idênticos } \\
\text { descendentes. }\end{array}$ & $\begin{array}{lrr}\text { Sim, com } & \text { quinhões } \\
\text { correspondentes } & \text { à } & \text { metade } \\
\text { dos } & \text { quinhões } & \text { dos } \\
\text { descendentes. } & \end{array}$ \\
\hline $\begin{array}{l}\text { CONCORRÊNCIA COM } \\
\text { DESCENDENTES } \\
\text { HÍBRIDOS }\end{array}$ & 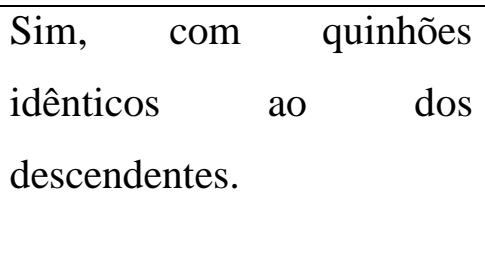 & 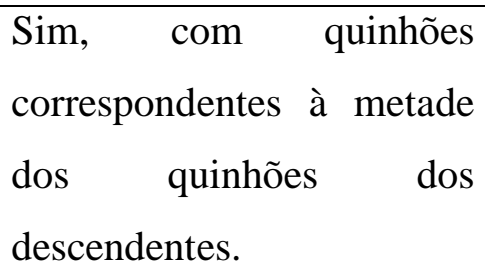 \\
\hline $\begin{array}{l}\text { CONCORRENCIA COM } \\
\text { OS } 2 \text { ASCENDENTES DO } \\
\text { DE CUJUS }\end{array}$ & $\begin{array}{l}\text { Sim, garantido o direito a } \\
1 / 3 \text { da herança. }\end{array}$ & $\begin{array}{l}\text { Sim, garantido o direito a } \\
1 / 3 \text { da herança. }\end{array}$ \\
\hline $\begin{array}{l}\text { CONCORRENCIA COM } \\
1 \text { DOS ASCENDENTES } \\
\text { DO DE CUJUS }\end{array}$ & $\begin{array}{l}\text { Sim, garantido o direito a } \\
1 / 3 \text { da herança. }\end{array}$ & $\begin{array}{l}\text { Sim, garantido o direito a } \\
1 / 3 \text { da herança. }\end{array}$ \\
\hline $\begin{array}{l}\text { TERCEIRO EXCLUSIVO } \\
\text { NA ORDEM DA } \\
\text { VOCAÇÃO } \\
\text { HEREDITÁRIA }\end{array}$ & $\begin{array}{l}\text { Sim, recolhendo a herança } \\
\text { por inteiro, salvo eventual } \\
\text { testamento. }\end{array}$ & $\begin{array}{ll}\text { Concorrência com } & \text { os } \\
\text { colaterais, garantido } & \text { o } \\
\text { direito a } 1 / 3 \text { da herança. } & \end{array}$ \\
\hline $\begin{array}{l}\text { ATUALIDADE } \\
\text { RELAÇÃO }\end{array}$ & $30 \mathrm{CC}$ & 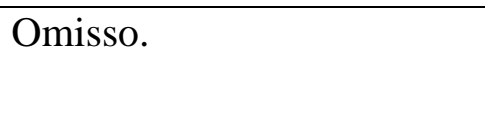 \\
\hline $\begin{array}{l}\text { DIREITO REAL } \\
\text { HABITAÇÃO }\end{array}$ & art. $1831 \mathrm{CC}$ & $\begin{array}{l}\text { Enunciado } 117, \text { I jornada } \\
\text { de direito civil. }\end{array}$ \\
\hline POSIÇÃO & $\mathrm{CC}$ & \\
\hline
\end{tabular}




\begin{tabular}{|c|c|c|}
\hline $\begin{array}{l}\text { HERDEIRO } \\
\text { NECESSÁRIO }\end{array}$ & & \\
\hline $\begin{array}{l}\text { DOAÇÃO DE BENS - } \\
\text { ADIANTAMENTO DE } \\
\text { HERANÇA }\end{array}$ & art. $544 \mathrm{CC}$ & art. $544 \mathrm{CC}$ \\
\hline $\begin{array}{l}\text { COLAÇÃO DE } \\
\text { DOADNS } \\
\text { DOS }\end{array}$ & art. $2003 \mathrm{CC}$ & Interpretação sistemática. \\
\hline OUTORGA CONJUGAL & art. $1647 \mathrm{CC}$ & $\begin{array}{l}\text { Divergência doutrinaria e } \\
\text { jurisprudencial. }\end{array}$ \\
\hline $\begin{array}{l}\text { OUTORGA CONJUGAL } \\
\text { - direito processual }\end{array}$ & $\begin{array}{l}\text { CPC, art. 10. O cônjuge } \\
\text { somente necessitará do } \\
\text { consentimento do outro } \\
\text { para propor ações que } \\
\text { versem sobre direitos reais } \\
\text { imobiliários (redação dada } \\
\text { pela lei 8.952, de } \\
\text { 13.12.1994). }\end{array}$ & $\begin{array}{l}\text { NCPC, art. 73. O cônjuge } \\
\text { necessitará } \\
\text { consentimento do outro } \\
\text { para propor ação que verse } \\
\text { sobre direito real } \\
\text { imobiliário, salvo quando } \\
\text { casados sob o regime de } \\
\text { separação absoluta de bens. } \\
\S 3 .^{\circ} \text { aplica-se o disposto } \\
\text { neste artigo à união estável } \\
\text { comprovada nos autos. }\end{array}$ \\
\hline
\end{tabular}

Discutir esses temas é necessário e relevante, possibilitando conhecer o percurso histórico e de debates no judiciário para atingir esse resultado. Trata-se de um lugar no qual a Constituição atua para afetar direitos fundamentais das famílias. Esse é o direito civil contemporâneo, garantidor do direito das gentes.

8. Alguns outros ajustes a serem observados.

A partir da verificação das diferenças e similitudes entre os sistemas familiares e seus impactos no direito sucessório, é possível inferir que outro tratamento deve ser atribuído a determinados institutos. A necessidade advém da adequação da interpretação sistemática, com a extensão de alguns efeitos jurídicos aos companheiros. 
No caso de adiantamento de herança de bens doados e suscetíveis de colação ${ }^{20}$, o art. 2003 do Código Civil não menciona o companheiro como legitimado a igualar os quinhões. No entanto, conviventes são herdeiros necessários e atendendo a interpretação sistemática ${ }^{21}$ (LÔBO, 2018), também devem colacionar os bens recebidos em doação, pois herdeiros legítimos.

O raciocínio deve ser estendido às questões referentes a deserdação. O Código deixa de mencionar especificamente cônjuge e convivente para a hipótese. A regra geral de exclusão dos herdeiros necessários será aplicada a cônjuges e companheiros supérstites, herdeiros necessários e concorrentes, sendo possível a deserdação nas mesmas hipóteses de caracterização da indignidade.

Outra questão relevante está na interpretação do art. 1647 do Código Civil no que tange a outorga conjugal para a alienação de bens imóveis particulares no regime da comunhão parcial de bens. A lei expressamente exige como regra a intervenção do cônjuge para a alienação ${ }^{22}$, considerando eventual interesse familiar na manutenção do patrimônio. A norma é taxativa para o casamento e discute-se a sua aplicação em relações estáveis.

Por ser uma norma restritiva de direitos a exigir a intervenção de um terceiro na manifestação da vontade, no caso o companheiro, é possível considerar pela não aplicabilidade para as uniões informais, já que delas não trata o referido artigo ${ }^{23}$ (TARTUCE, 2018). No caso, só é aplicável a "distinção quando a ratio da norma em exame tiver por fundamento a necessidade de publicidade que só encontra lugar no casamento" (enunciado 641 do Conselho de Justiça Federal).

De outro lado, há o interesse familiar na alienação de bens, ainda que particulares, na medida em que eles podem ser o ambiente de domicílio ou de renda do grupo familiar. Ainda que o artigo não mencione taxativamente a união estável, a intervenção seria uma forma de resguardar a economia doméstica e a dignidade da entidade familiar. Alienar o bem sem que o companheiro sequer saiba ou ainda intervenha poderá colocar o grupo em risco. Se a pretensão é de proteção, não há sentido em admitir para uma configuração e não para a outra.

A reflexão se dá em razão das formações das famílias e também no que se refere à intervenção estatal na vontade privada e o quão excessivo ela é. A linha parece tênue entre um

\footnotetext{
20 art. 544 do Código Civil.

${ }^{21}$ VIII Jornada de Direito Civil, CJF, Enunciado 644, art. 2003: Os arts. 2003 e 2004 do Código Civil e o art. 639 do CPC devem ser interpretados de modo a garantir a igualdade das legítimas e a coerência do ordenamento. 22 IV Jornada de Direito Civil, CJF, Enunciado 340: No regime da comunhão parcial de bens é sempre indispensável a autorização do cônjuge, ou seu suprimento judicial, para atos de disposição sobre bens imóveis.

${ }^{23}$ Informativo n. 535, 2014, STJ.
} 
estado liberal com o aparente paradoxo de ser o garantidor da dignidade das entidades familiares em todos os seus aspectos. Para caminhar e dar contorno possível à circulação de riquezas, a liberdade de escolhas e a proteção às famílias, acredita-se que deverá ser feita uma escolha que trate com igualdade as formações familiares, já que ao final elas têm como questão e fundo a solidariedade familiar.

Propõe-se pensar sobre a possível interpretação sistemática da totalidade do art.1647 do Código Civil. No caso, considerando que o art.1725 do Código Civil orienta a aplicação do regime da comunhão parcial de bens para a união estável, salvo na hipótese de contrato escrito, e o regime supletório impõe o consentimento conjugal nos casos do art. 1647 do Código Civil, deve-se intervir em ambas as hipóteses. O interesse é da unidade ou multiplicidade familiar.

Em 2015 o STJ decidiu que se faz necessária a outorga em se tratando de união estável pública e registrada ${ }^{24}$, o que desnatura a própria natureza da união estável: ela não pode ser considerada caso não seja pública e tampouco deve ser obrigatoriamente registrada para ser reconhecida, pois se trata de um fato jurídico. E o registro é uma modalidade de prova, mas não absoluta.

Além desses aspectos, o Código de Processo Civil (CPC) de $2015^{25}$ determina a outorga conjugal e amplia o escopo de atuação aos conviventes com união estável comprovada nos autos em ações que versem sobre direitos reais imobiliários, em identidade jurídica e idêntica ao casamento. Há aqui a necessidade de comprovação, ou seja, uma formalização a aproximar e que suscita nova questão para saber se a outorga convivencial se aplica apenas do inciso II do art.1647 do Código Civil (TARTUCE, 2018) ou se o atinge na totalidade.

Ainda no que se refere à outorga, o STJ reconhece a prestação de fiança sem autorização conjugal ${ }^{26}$ e a consequente penhora de bem indivisível na hipótese de execução. Ora, em caso de inadimplemento contratual, poderá haver a constrição do bem e a perda dele. A proteção à entidade familiar também ficaria afetada.

\footnotetext{
${ }^{24}$ Informativo 0554, 2015, STJ: Direito civil. Alienação, sem consentimento do companheiro, de bem imóvel adquirido na constância da união estável. A invalidação da alienação de imóvel comum, fundada na falta de consentimento do companheiro, dependerá da publicidade conferida à união estável, mediante a averbação de contrato de convivência ou da decisão declaratória da existência de união estável no Ofício do Registro de Imóveis em que cadastrados os bens comuns, ou da demonstração de má-fé do adquirente.

${ }^{25}$ Código de Processo Civil, Art. 73, § 3은

${ }^{26}$ Agravo Interno nos embargos de declaração no recurso especial. AgInt nos EDcl no REsp 1711164 / DF, Agravo interno nos embargos de declaração no recurso especial, 2017/0296847-4. Julgado em 24/09/2018. Embargos de terceiro. Penhora de imóvel. União estável. Outorga uxória. Desnecessidade.
} 
São temas objeto de reflexão, também a partir do novo CPC, as idênticas posições jurídicas do cônjuge e do companheiro no que se refere à legitimidade para requerer o inventário e partilha ${ }^{27}$ e a ordem preferencial para o exercício da inventariança ${ }^{28}$. Não se trata de equiparação, mas de reconhecimento de posição jurídica idêntica como herdeiros necessários.

Os comandos legais que se aproximam do acolhimento das famílias plurais permitem "a leitura constitucional como sendo iguais todas as entidades familiares, a distinção evidenciada no Código Civil de 2002 é tida como uma inaceitável discriminação" (RIZZARDO, 2018). Não havendo hierarquia entre elas, cônjuges e companheiros supérstites sucedem em igualdade de condições.

\section{CONSIDERAÇÕES FINAIS}

As diferenças normativas garantidoras para as famílias matrimoniais foram instituídas de formas tão distintas em relação à união estável a ponto de gerar distopias. São situações em que a proteção à integridade da família fica abalada pelo tratamento diferenciado. No caso em específico do art. 1790 do Código Civil, as discrepâncias baseadas nos mais diferentes aspectos sociais e culturais. Exatamente por essas razões o artigo é objeto de controvérsias e demandou a decisão com repercussão geral.

Foram também identificadas normas bem diferentes com aplicações díspares para situações com questões de fundo semelhantes. As diferenças normativas e as semelhanças fáticas entre os dois regimes familiares e sucessórios aplicados para as uniões formais e informais geram discussões desde o início da vigência da norma. A posição de vantagem jurídica do cônjuge em face do companheiro aliada à simbologia religiosa e social do casamento cristalizou a preferência sobre a união estável. Essa preza pela informalidade em sua formação, aquele é cartorial, formal e rígido. Ambas comportam efeitos jurídicos familiares, ainda que diferentes em sua origem, aplicando a analogia majoritariamente às regras de solidariedade, mas não às de rigor formal ${ }^{29}$. No entanto, a abordagem deve se dar

\footnotetext{
${ }^{27}$ Código de Processo Civil, Art. 616, I.

${ }^{28}$ Código de Processo Civil, Art. 617, I.

29 VIII Jornada CJF, Enunciado 641:“A decisão do Supremo Tribunal Federal que declarou a inconstitucionalidade do art. 1.790 do Código Civil não importa equiparação absoluta entre o casamento e a união estável. Estendem-se à união estável apenas as regras aplicáveis ao casamento que tenham por fundamento a solidariedade familiar. Por outro lado, é constitucional a distinção entre os regimes, quando baseada na solenidade do ato jurídico que funda o casamento, ausente na união estável".
}

Rev. de Direito de Família e Sucessões | e-ISSN: 2526-0227 | Goiânia| v. 5 | n. 1 | p. 1-20| Jan/Jun. 2019 
em favor das famílias, admitindo-se o manuseio de e todos os instrumentos garantidores das igualdades.

Esses confrontos exigiram da doutrina e da jurisprudência acomodar a interpretação do Código Civil à nova ordem. No caso, o ativismo efetivamente se fez presente através do STF. Ao decidir pela igualdade jurídica entre as configurações familiares e declarar inconstitucional o art. 1.790 do CC, específico e discriminador aos direitos dos companheiros, orientando que a partir de então seja aplicado o artigo 1.829 do CC para todas as sucessões, e não apenas as decorrentes da família matrimonial, surgem necessidades de ajustes normativos em outros institutos para que efetivamente não haja classes de famílias.

A desconstrução da prevalência de um instituto sobre o outro é lenta. Manter sistemas distintos sob o argumento que as entidades familiares se constituem sob as mais distintas modalidades não traduzia a preocupação com a dignidade da pessoa humana e a importância das famílias para o indivíduo e para a sociedade. É preciso sair do senso comum. O direito é fenômeno complexo e a interpretação contemporânea de reconhecimento às igualdades em direitos sucessórios para todas as formações familiares merece atenção para impedir a estagnação e retrocessos sociais.

O sistema cíclico de construção sociedade-direito-sociedade exige a avaliação dos fatos sociais para a transformação de uma norma. A provocação ao direito para respostas às suas demandas exige resultados. A perspectiva sociológica deve ser observada de forma organizada para tornar possível a descrição e interpretação dos fenômenos sociais e as reações a determinados problemas, ao considerar essas influencias como fontes materiais do direito. $\mathrm{O}$ rigor formal de determinados artigos dos Códigos não substitui o saber jurídico, operando a interpretação do Judiciário para integralizar a resposta social em uma sociedade que transforma o direito.

\section{REFERÊNCIAS BIBLIOGRÁFICAS}

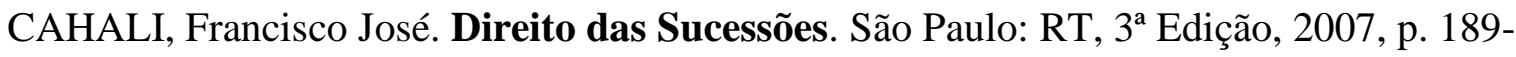
192.

CARVALHO, Luiz Paulo Vieira de. Direito das sucessões. 3. ed. rev., atual. e ampl. - São Paulo: Atlas, 2017.

FACHIN, Luiz Edson. Estatuto do patrimônio mínimo. 2. ed. Rio de Janeiro: Renovar, 2006.

FROTA, Pablo Malheiros da Cunha. O direito real de habitação e a sua possível relativização no direito sucessório brasileiro: primeiras reflexões. Revista de Direito Civil Contemporâneo 2016 RDCC VOL. 8. julho - setembro 2016. 
GAGLIANO, Pablo Stolze e PAMPLONA FILHO, Rodolfo. Novo Curso de Direito Civil. Direito das famílias. A família em perspectiva constitucional. 6 ed. revista, atualizada e ampliada. São Paulo: Saraiva, 2018.

HIRONAKA, Giselda Maria Fernandes. Comentários ao Código Civil. Vol. 20. Coord. Antonio Junqueira de Azevedo. São Paulo: Saraiva, $2^{a}$ Edição, 2007, p. 228-229;

LÔBO, Paulo. Direito Civil: Famílias. Vol. 5. São Paulo: Saraiva, $8^{\text {a }}$ Ed. 2018 TARTUCE, Flávio; SIMÃO, José Fernando. Direito Civil. Vol. 6. Direito das Sucessões. São Paulo: GEN/Método, $3^{\text {a }}$ Edição, 2017.

PEREIRA, Caio Mário da Silva. Instituições de Direito Civil. Volume V. Direito de família. $24^{\mathrm{a}}$ edição Rio de Janeiro: Forense, 2017.

PEREIRA, Rodrigo da Cunha. Divórcio - teoria e prática. São Paulo: Saraiva, 2016.

RIZZARDO, Arnaldo. Direito das sucessões. 10. ed., rev. atual. ampl. - Rio de Janeiro: Forense, 2018.

TARTUCE, Flávio. Direito civil, v. 5 : Direito de Família. 13. ed. rev., atual. e ampl. - Rio de Janeiro: Forense, 2018.

VELOSO, Zeno. Direito sucessório dos companheiros. III Congresso Brasileiro de Direito de Família Ouro Preto - MG - Outubro de 2001. Disponível em

http://www.ibdfam.org.br/_img/congressos/anais/188.pdf

\section{LEGISLAÇÃO}

BRASIL, Lei n ${ }^{\circ} 3.071$, de $1^{\circ}$ de janeiro de 1916. Institui o Código Civil. Diário Oficial da República Federativa do Brasil, Diário Oficial da União. Seção 1. 05/01/1916. p. 133.

. Lei $\mathrm{n}^{\circ} 4.121$, de 27 de agosto de 1962. Dispõe sôbre a situação jurídica da mulher casada. Diário Oficial da República Federativa do Brasil, Diário Oficial da União. 03/09/1962.

. Lei ${ }^{\circ} 6.515$ de 26 de dezembro de 1977. Lei do Divórcio. Diário Oficial da República Federativa do Brasil, Diário Oficial da União.29/12/1977. Constituição (1988). Constituição da República Federativa do Brasil. Brasília, DF: Senado Federal, 1988.

Lei $\mathrm{n}^{\circ}$ 8.971, de 29 de dezembro de 1994. Regula o direito dos companheiros a

alimentos e à sucessão. Diário Oficial da República Federativa do Brasil, Diário Oficial da União. 30/12/1994.

Lei $\mathrm{n}^{\circ}$ 9.278, de 10 de maio de 1996. Regula o $\S 3^{\circ}$ do art. 226 da Constituição

Federal. Diário Oficial da República Federativa do Brasil, Diário Oficial da União. 13/05/1996.

Lei $\mathrm{n}^{\circ} 10.406$, de 11 de janeiro de 2002. Institui o Código Civil. Diário Oficial da República Federativa do Brasil, Diário Oficial da União. - Seção 1 - 11/1/2002, Página 1.

SITES

http://portal.stf.jus.br 